\title{
Decreased V $\beta 8.2$ T-cells in neonatal rats exposed prenatally to Staphylococcal enterotoxin $B$ are further deleted by restimulation in an in vitro cultured thymus
}

\author{
WEN-XUAN YANG ${ }^{1 *}$, XIANG ZHU ${ }^{1,2 *}$, FENG-LING YU ${ }^{1 *}$, TAO ZHANG $^{1,3}$, NA LIN $^{1}$, TING-TING LIU ${ }^{1,3}$, \\ FANG-FANG ZHAO ${ }^{1,3}$, YONG LIU ${ }^{1,3}$, HUI XIA ${ }^{1}$ and JUN-CHANG GUAN ${ }^{1,3}$ \\ ${ }^{1}$ Anhui Key Laboratory of Infection and Immunity; ${ }^{2}$ Department of Blood Transfusion, The First Affiliated Hospital; \\ ${ }^{3}$ Department of Microbiology, Bengbu Medical College, Bengbu, Anhui 233030, P.R. China
}

Received December 2, 2013; Accepted April 25, 2014

DOI: $10.3892 / \mathrm{mmr} .2014 .2270$

\begin{abstract}
Staphylococcal enterotoxin B (SEB) administration during adulthood can cause the anergy or deletion of variable portion of the $\beta$ chain ( $\mathrm{V} \beta$ )-expressing $\mathrm{T}$ cells. However, the effect of maternal SEB administration during pregnancy on the thymocytes of neonatal rats remains to be elucidated. In the present study, pregnant rats at gestational day 16 were intravenously injected with $15 \mu \mathrm{g}$ SEB. The present study revealed that prenatal exposure of SEB significantly increased the proportion of cluster of differentiation (CD)4-single positive (SP) T cells and decreased the proportions of CD8-SP, $\mathrm{CD}^{+} \mathrm{V} \beta 8.2^{+}$and $\mathrm{CD} 8^{+} \mathrm{V} \beta 8.2^{+} \mathrm{T}$ cells in the thymus of neonatal rats between day 0 and 5 after delivery. In an in vitro cultured thymus, SEB restimulation significantly increased the proportion of double positive cells and decreased the proportions of CD4-SP, CD8-SP, CD4 ${ }^{+} \mathrm{V} \beta 8.2^{+}$and $\mathrm{CD}^{+}$ $\mathrm{V} \beta 8.2^{+} \mathrm{T}$ cells. Furthermore, the decreased V $\beta 8.2^{+} \mathrm{T}$-cells in neonatal rats exposed prenatally to SEB were further deleted by SEB restimulation in an in vitro cultured thymus. These data suggested the special response pattern of the remaining SEB-specific $T$ cells to SEB restimulation in neonatal rats exposed prenatally to SEB.
\end{abstract}

\section{Introduction}

The thymus is a primary lymphoid organ and is important in inducing and supporting the proliferation and differentiation

Correspondence to: Professor Jun-Chang Guan, Department of Microbiology, and Anhui Key Laboratory of Infection and Immunity, Bengbu Medical College, 2600 Dong Hai Avenue, Bengbu, Anhui 233030, P.R. China

E-mail: guanjc2013@126.com

*Contributed equally

Key words: V $\beta 8.2 \mathrm{~T}$ cells, staphylococcal enterotoxin B, thymus culture, pregnancy of early thymocyte progenitors into $\mathrm{T}$ cells $(1,2)$. Thymocyte differentiation initiates with migration of common lymphoid progenitor cells from hematopoietic stem cells in fetal liver or adult bone marrow into the thymus, where they undergo cellular maturation and T-cell receptor (TCR)-based selection. The thymic microenvironment (a complex mixture of epithelial cells, interdigitating dendritic cells, macrophages and fibroblastoid cells) $(3,4)$, pre-TCR $(5,6)$ and signaling pathway molecules, including bone morphogenetic protein and Notch $(7,8)$, are important in thymocyte differentiation and development. Distinct developmental compartments in the thymus have been defined according to the expression of the cluster of differentiation (CD) 4 and CD8 co-receptors on differentiating thymocytes. The earliest compartment consists of $\mathrm{CD}^{-\mathrm{CD}} 8^{-}$double negative (DN) thymocytes that trasnform into $\mathrm{CD}^{+}{ }^{+} \mathrm{CD} 8{ }^{+}$double positive (DP) intermediates, which give rise to a mature $\mathrm{CD}^{+}{ }^{+} \mathrm{CD} 8-(\mathrm{CD} 4)$ or $\mathrm{CD}^{-} \mathrm{CD}^{+}(\mathrm{CD} 8)$ single positive (SP) mature progeny (9).

Staphylococcal enterotoxin B (SEB) is not only a toxic substance but also an important superantigen (SAg), which has been extensively investigated in five groups (A through $\mathrm{E}$ ) of staphylococcal enterotoxin (10). SEB as a SAg can cross-link major histocompatibility complex class II molecules with a variable portion of the $\beta$ chain $(\mathrm{V} \beta)$ of the TCR, binding beyond the antigen-specific site, which does not require classical antigen-processing and presentation and is able to polyclonally stimulate T cells (11). Several studies $(12,13)$ have demonstrated that the immune response to SAg is biphasic: an initial activation phase characterized by T-cell proliferation is followed by a period of anergy and/or tolerance owing to deletion of the appropriate $\mathrm{V} \beta$-expressing $\mathrm{T}$ cells by apoptosis. Besides the immune response of $\mathrm{T}$ cells to SEB, SEB administration is able to cause thymus atrophy (14) and alter the percentages or numbers of CD4/CD8 T cells in the thymus (14-16). Although numerous studies have investigated the effect of SEB administration during adulthood or the neonatal period on immune organs and $\mathrm{T}$ cells, the effect of maternal SEB administration during pregnancy on thymocytes of neonatal rats remains to be elucidated. Therefore, in the present study, pregnant rats at gestational day (GD) 16 were injected intravenously with $15 \mu \mathrm{g}$ SEB. CD4/CD8 T cells and 
$\mathrm{V} \beta 8^{+} \mathrm{T}$ cells subpopulation were determined in the thymus of neonatal rats between day 0 and 5 after delivery. The effect of SEB on thymocyte development was also investigated using an in vitro cultured neonatal thymus organ.

\section{Materials and methods}

Animals. Three-month-old Sprague-Dawley rats were used in the present study and housed in a controlled environment of $22-25^{\circ} \mathrm{C}$ and a $12-\mathrm{h}$ light/dark cycle, with rodent chow and filtered tap water provided ad libitum. Each female rat was mated with a male rat and checked each morning for the presence of a vaginal plug. Day 1 of gestation (GD) was defined as the day when a plug was initially observed in the vagina. When the pregnancy was confirmed, the females were isolated from the males and kept in separate cages. Timed pregnant rats were randomly divided into the following two groups at GD 16: the control [(phosphate-buffered saline (PBS)] group and the SEB group. In the SEB group, the pregnant rats were intravenously injected once with $0.3 \mathrm{ml} 50 \mu \mathrm{g} / \mathrm{ml} \mathrm{SEB}$ (Sigma-Aldrich, St. Louis, MO, USA) in 0.2 M PBS. The pregnant rats in the PBS group were intravenously injected once with the same volume of PBS. The thymi of neonatal rats were acquired for experiments between day 0 and 5 after delivery. The present study was approved by the Animal Research Ethics Committee of Bengbu Medical College (Bengbu, Anhui, China).

Preparation of neonatal thymocyte suspensions. Between day 0 and 5 after delivery, the thymi of neonatal rats were teased apart, minced, pressed through a $100-\mathrm{mm}$ fine wire mesh screen and collected in balanced PBS solution supplemented with $2 \%$ heat-inactivated fetal bovine serum (FBS; HyClone, Logan, UT, USA). The cells were washed twice with PBS, centrifuged at $400 \mathrm{xg}$ for $10 \mathrm{~min}$ at $4^{\circ} \mathrm{C}$, and resuspended in staining buffer (PBS containing $2 \% \mathrm{FBS}$ and $0.02 \% \mathrm{NaN}_{3}$ ). Nucleated cells were counted in a Burker-Turk hemocytometer (Emergo, Landsmeer, Netherlands) by using a microscope (Leica DM500; Leica Microsystems, Wetzlar, Germany) and $10^{6}$ cells were stained for flow cytometric analysis as described below.

Neonatal thymus organ culture. Neonatal thymus organ culture was processed as previously described for fetal thymus organ culture (17). Briefly, on the day following delivery, the thymus lobes of neonatal rats were dissected, and rinsed three times in sterile HEPES-buffered RPMI-1640 (Gibco-BRL, Carlsbad, CA, USA). Thymus lobes were placed on the surface of Millipore filters ( $25 \mu \mathrm{m}$ thick, $0.8-\mu \mathrm{m}$ pore size; Millipore, San Francisco, CA, USA) supported on the top of surgical Gelfoam sponge (Jinling Pharmaceutical Co., Nanjing, China). Each Gelfoam sponge was hydrated overnight in 24-well tissue culture plates containing $2 \mathrm{ml}$ RPMI-1640 (4.5 g/l D-glucose) supplemented with $100 \mathrm{U} / \mathrm{ml}$ penicillin, $100 \mu \mathrm{g} / \mathrm{ml}$ streptomycin, $10 \mu \mathrm{g} / \mathrm{ml}$ gentamicin, $2 \mathrm{mM}$ glutamine, $0.1 \mathrm{mM}$ nonessential amino acids, $0.02 \mathrm{mM}$ 2-mercaptoethanol, $3.4 \mathrm{~g} / 1$ sodium bicarbonate, $1 \mathrm{mM}$ sodium pyruvate and $20 \%$ heat-inactivated FBS Thymus lobes were cultured for three days in culture plates in a humidified incubator in $5 \% \mathrm{CO}_{2}$ at $37^{\circ} \mathrm{C}$. At the beginning of the culture, neonatal thymus lobes in each group were co-cultured with $100 \mathrm{ng} / \mathrm{ml} \mathrm{SEB}$ added to the mediums. For harvesting at the end of culture, filters were removed from the cultures and placed tissue side down in sterile 6-well tissue culture plates containing $3 \mathrm{ml}$ of $0.4 \mathrm{mg} / \mathrm{ml}$ collagenase from Clostridium histolyticum Type IV (Sigma, St. Louis, MO, USA) in $0.2 \mathrm{M}$ PBS with $0.2 \mathrm{mg} / \mathrm{ml}$ ethylenediaminetetraacetic acid. The tissue was digested for $30 \mathrm{~min}$ at $37^{\circ} \mathrm{C}$. Digestion was stopped by placing the plates on ice and by adding $0.5 \mathrm{ml}$ FBS to each well. Residual thymus tissue was flushed off from the filters by gentle aspiration with a Pasteur pipette (Yangzhou Goldenwell Medical Devices Factory, Jiangsu, China). Then, the lobes and residual thymus tissue were gently dispersed into a single cell suspension, washed twice by centrifugation $\left(400 \mathrm{x} \mathrm{g}\right.$ for $10 \mathrm{~min}$ at $\left.4^{\circ} \mathrm{C}\right)$ in HEPES-buffered RPMI-1640 and resuspended in staining buffer. The viable cell number was determined by trypan blue dye exclusion using a hemocytometer and was always $>95 \%$.

Flow cytometric analysis. Single cell suspensions obtained as above were stained using directly conjugated monoclonal antibodies specific for CD3, CD4, CD8, TCR V8.2/8.4 (eBioscience, San Diego, CA, USA) at $4^{\circ} \mathrm{C}$ for $30 \mathrm{~min}$, washed and then fixed with $1 \%$ paraformaldehyde. The labeled cells were then analyzed by flow cytometry on a FACS calibur (Becton Dickinson, Heidelberg, Germany) using CellQuest analysis software (BD Biosciences, Franklin Lakes, NJ, USA). Dead cells were excluded on the basis of low forward-light scatter.

Statistical analysis. The results are expressed as the mean \pm standard deviation. To assess significant differences in $\mathrm{T}$ cells in the thymus of neonatal rats between day 0 and 5 after delivery, Tukey's-b test in one-way analysis of variance was used. Independent t-test was used to assess the difference in $\mathrm{T}$ cells in the in vitro cultured thymus of neonatal rats. $\mathrm{P}<0.05$ was considered to indicate a statistically significant difference.

\section{Results}

Effect of prenatal exposure of SEB on CD4/CD8 cells in the thymus of neonatal rats. Pregnant rats at GD 16 were intravenously administered $15 \mu \mathrm{g}$ SEB and the thymi of neonatal rats between day 0 and 5 after delivery were acquired to determine the proportion of CD4/CD8 cells. Fig. 1 shows the analysis of $\mathrm{T}$ cells subset in neonatal thymi by flow cytometry. Between day 0 and 5 after delivery, the proportion of thymic CD4-SP cells in the SEB group was significantly higher than that in the PBS group, while the proportion of thymic CD8-SP cells in the SEB group was significantly lower than that in the PBS group. However, no difference in the proportion of DN and DP cells between the PBS and SEB groups was identified.

Prenatal exposure of SEB decreased the proportion of V $\beta 8.2^{+}$ $T$ cells of neonatal rats. Proportion of $\mathrm{V} \beta 8.2^{+} \mathrm{T}$ cells in the thymi of neonatal rats between day 0 and 5 was also determined. It was revealed that the proportion of thymic $\mathrm{CD} 4^{+}$ $\mathrm{V} \beta 8.2^{+} \mathrm{T}$ cells in the SEB group was significantly lower than that in the PBS group between day 0 and 3 after delivery, 
A
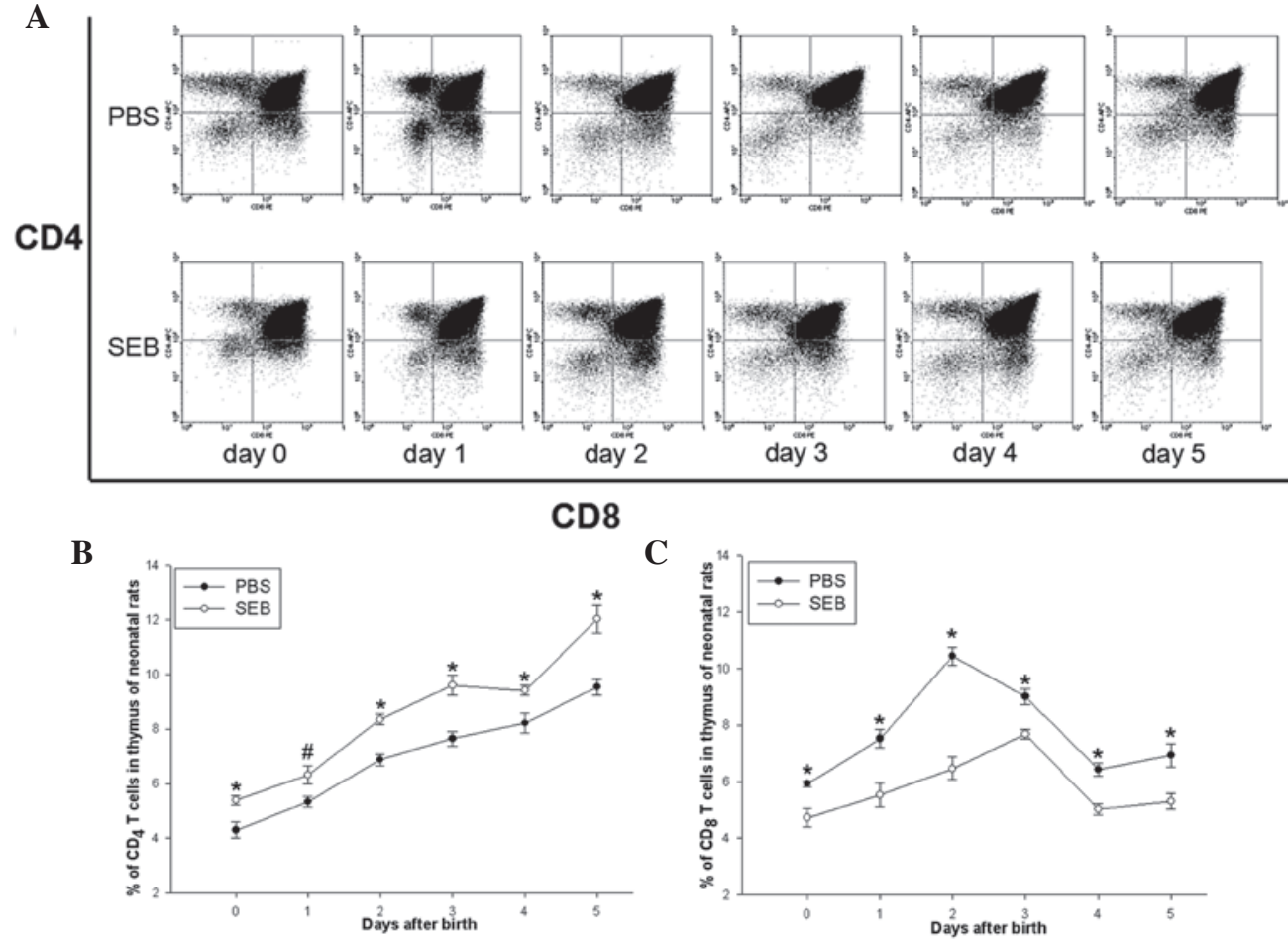

C

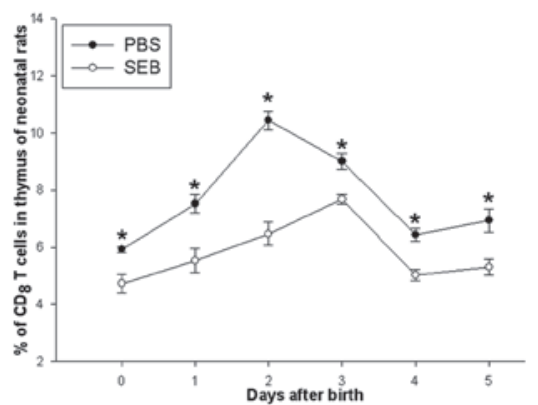

D

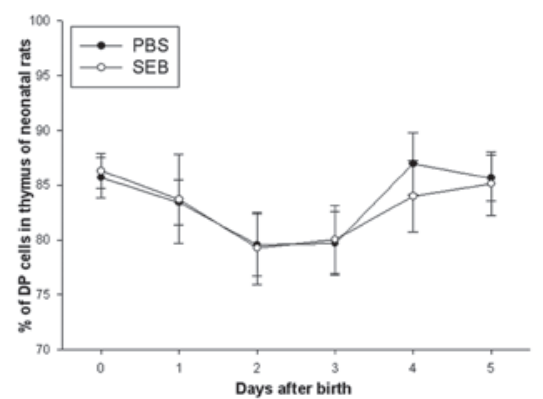

E

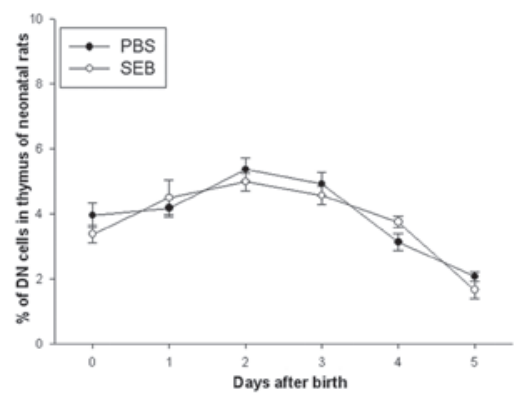

Figure 1. Effect of prenatal exposure of SEB on CD4/CD8 T cells in the thymus of neonatal rats. The thymi of neonatal rats between day 0 and 5 after delivery were harvested and analyzed by flow cytometry. (A) An example of dot plots of thymocytes obtained by flow cytometry is shown. CD8-phycoerythrin fluorescence is presented on the horizontal axis and CD4-allophycocyanin fluorescence on the vertical axis. The proportions of (B) CD4-SP, (C) CD8-SP, (D) DP and (E) DN cells in thymi were analyzed by flow cytometry. Values were calculated with data from six experiments. Compared with the PBS group at each time point: ${ }^{\#} \mathrm{P}<0.05 ;{ }^{*} \mathrm{P}<0.01$. SEB, staphylococcal enterotoxin B; SP, single positive; DP, double positive; DN, double negative; PBS, phosphate-buffered saline; $\mathrm{CD}$, cluster of differentiation.

A

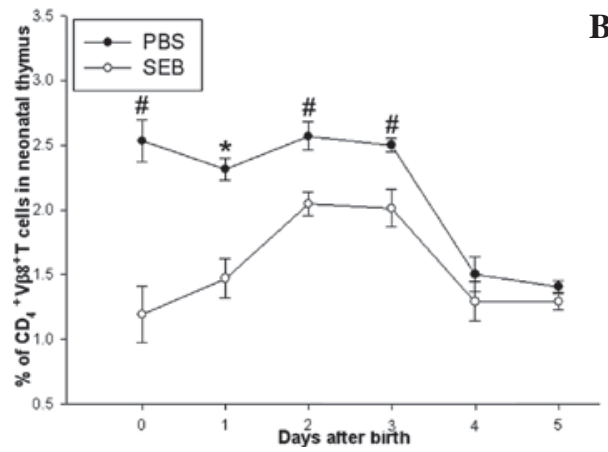

B

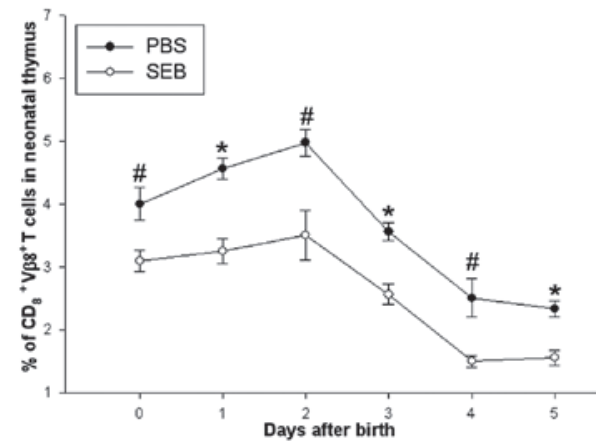

Figure 2. Effect of prenatal exposure of SEB on V $\beta 8.2^{+} \mathrm{T}$ cells in the thymus of neonatal rats. The thymi of neonatal offspring rats between day 0 and 5 after delivery were harvested and analyzed by flow cytometry for (A) $\mathrm{CD}^{+} \mathrm{V} \beta 8.2^{+}$and (B) $\mathrm{CD} 8^{+} \mathrm{V} \beta 8.2^{+} \mathrm{T}$ cells. Values were calculated with data from six experiments. Compared with the PBS group at each time point: ${ }^{\#} \mathrm{P}<0.05 ;{ }^{*} \mathrm{P}<0.01$. SEB, staphylococcal enterotoxin $\mathrm{B}$; PBS, phosphate-buffered saline; V $\beta$, variable portion of the $\beta$ chain; $\mathrm{CD}$, cluster of differentiation.

however, no difference in the two groups was observed between day 4 and 5 . While the proportions of thymic $\mathrm{CD}^{+}$
$\mathrm{V} \beta 8.2^{+} \mathrm{T}$ in the SEB group were lower than that in the PBS group between day 0 and 5 after delivery (Fig. 2). 
A

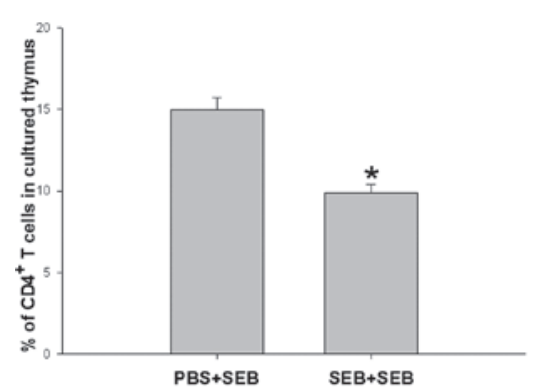

C

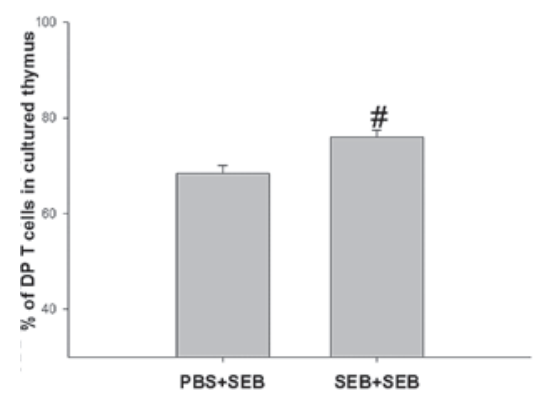

B

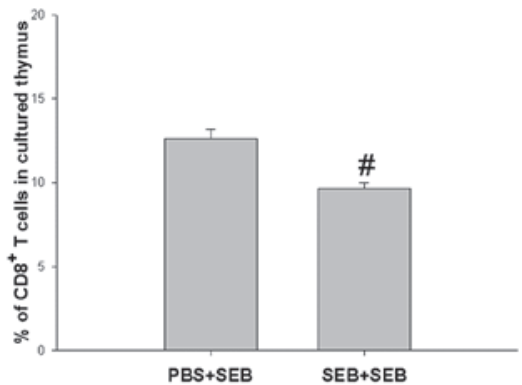

D

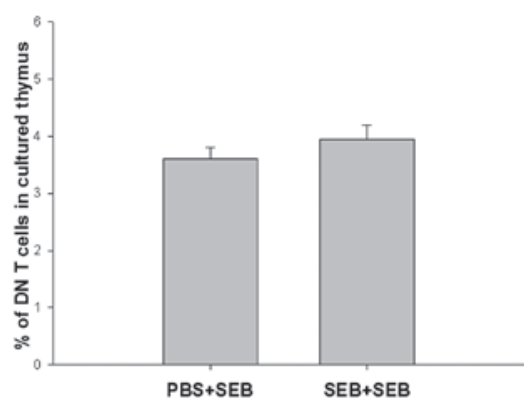

Figure 3. Effect of SEB restimulation on CD4/CD8 T cells in an in vitro cultured thymus of neonatal rats. At the day of delivery, the thymi of neonatal rats in the PBS and SEB groups were co-cultured in vitro with SEB for three days. The thymocytes were analyzed by flow cytometry for the proportions of (A) CD4-SP, (B) CD8-SP (C) DP and (D) DN T cells. Values were calculated with data from four experiments performed in triplicate. Compared with the PBS group at the co-culture of SEB: " $\mathrm{P}<0.05 ;{ }^{*} \mathrm{P}<0.01$. SEB, staphylococcal enterotoxin B; PBS, phosphate-buffered saline; SP, single positive; DP, double positive; $\mathrm{DN}$, double negative; $\mathrm{CD}$, cluster of differentiation.

A

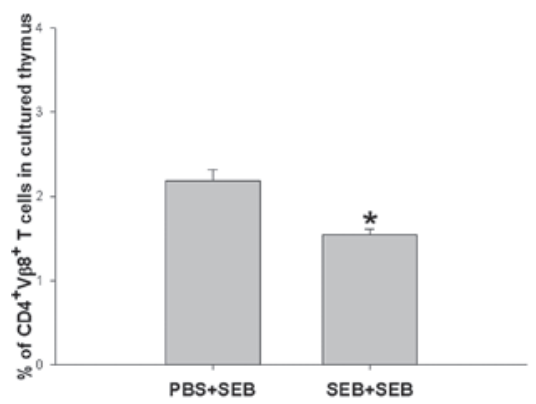

B

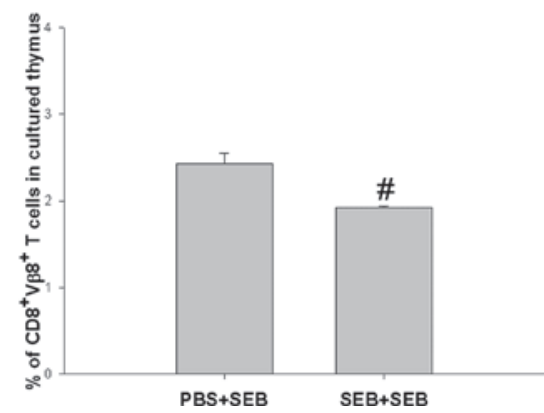

Figure 4. Effect of SEB restimulation on $\mathrm{V} \beta 8.2^{+} \mathrm{T}$ cells in the in vitro cultured thymus of neonatal rats. At the day of delivery, the thymi of neonatal rats in the PBS and SEB groups were co-cultured in vitro with SEB for three days. The thymocytes were analyzed by flow cytometry for the proportions of (A) CD $4^{+}$ $\mathrm{V} \beta 8.2^{+}$and (B) $\mathrm{CD}^{+} \mathrm{V} \beta 8.2^{+} \mathrm{T}$ cells. Values were calculated with data from four experiments performed in triplicate. Compared with the PBS group at the co-culture of SEB: ${ }^{\#} \mathrm{P}<0.05$; ${ }^{*} \mathrm{P}<0.01$. SEB, staphylococcal enterotoxin $\mathrm{B}$; PBS, phosphate-buffered saline; V $\beta$, variable portion of the $\beta$ chain; $\mathrm{CD}$, cluster of differentiation.

Effect of SEB restimulation on CD4/CD8 cells in the in vitro cultured thymus of neonatal rats. In order to investigate the response of neonatal thymocytes to SEB restimulation, the in vitro culture of thymus was used. The thymi of neonatal rats on the day following delivery in the PBS and SEB groups were co-cultured with $100 \mathrm{ng} / \mathrm{ml} \mathrm{SEB}$ for three days. At the end of the culture, it was found that the proportions of CD4-SP and CD8-SP cells in the SEB group were significantly decreased compared with that in the PBS group in the in vitro co-cultured thymus with SEB for three days, however, the proportion of DP cells was significantly increased. While no difference was identified in the proportion of DN cells between the two groups (Fig. 3).

$S E B$ restimulation decreases the proportion of $V \beta 8.2^{+} T$ cells in the in vitro cultured thymus of neonatal rats. The proportion of $\mathrm{V} \beta 8.2^{+} \mathrm{T}$ cells in the in vitro cultured thymus of neonatal rats was also determined. Following in vitro co-culture with
SEB for three days, proportions of $\mathrm{CD}^{+} \mathrm{V} \beta 8.2^{+}$and $\mathrm{CD} 8^{+}$ $\mathrm{V} \beta 8.2^{+} \mathrm{T}$ cells in the SEB group were significantly decreased compared with that in the PBS group (Fig. 4).

\section{Discussion}

In the present study, the effect of prenatal exposure of SEB on the thymocyte development of neonatal rats and the role of secondary SEB administration on the thymocytes in an in vitro cultured thymus was examined. The results from the present study demonstrated that prenatal exposure of SEB significantly increased the proportion of CD4-SP T cells, and decreased the proportions of CD8-SP, $\mathrm{CD}^{+} \mathrm{V} \beta 8.2^{+}$and $\mathrm{CD}^{+}$ $\mathrm{V} \beta 8.2^{+} \mathrm{T}$ cells. In the in vitro cultured thymus, secondary SEB administration significantly increased the proportion of DP cells, and decreased the proportions of CD4-SP, CD8-SP, $\mathrm{CD}^{+} \mathrm{V} \beta 8.2^{+}$and $\mathrm{CD} 8^{+} \mathrm{V} \beta 8.2^{+} \mathrm{T}$ cells. To the best of our knowledge, this is the first study to link prenatal SEB exposure 
to alterations in thymocyte development in neonatal offspring rats.

The thymus is an organ vital to the proper development of T lymphocytes from early thymocyte progenitors $(2,18)$ to differentiation into functional competent $\mathrm{T}$ cells ready for emigration to the periphery. Thymocytes at different stages express distinct phenotypes. According to the cell phenotypes defined by expression of the TCR complex, CD4 and/or CD8 coreceptors, thymocytes can be divided into the following four major subsets: DN, DP, CD4-SP and CD8-SP thymocytes. The developmental sequence of thymocytes in the fetal thymus can be delineated as follows: $\mathrm{DN} \rightarrow \mathrm{DP} \rightarrow \mathrm{TCR} \alpha \beta+\mathrm{CD} 4 / \mathrm{CD} 8 \mathrm{SP}$ pathway (19). Several studies have reported the effect of SEB on the population of thymocytes at different stages in adult animals. Goettelfinger et al (16) reported that intrathymic injection of SEB to adult mice significantly induced the depletion of CD8-SP cells in the thymus. Other studies have demonstrated that SEB injected intravenously into adult mice decreased the cell number of CD4-SP (15) and DP thymocytes (14) via apoptosis. However, the effect of SEB administration during pregnancy on the thymocytes of neonatal rats remains to be elucidated. The present data demonstrated that prenatal exposure of SEB was able to induce the decrease in the percentage of CD8-SP cells accompanied by a relative increase in the percentage of CD4-SP cells, but did not alter the percentage of DN and DP cells in the thymus of neonatal rats. In order to investigate the response of neonatal thymocytes to SEB restimulation, the in vitro culture of thymus was used in neonatal rats on the day following delivery was used. The present study found that secondary SEB administration in the in vitro cultured thymus was able to significantly decrease the percentage of CD4-SP and CD8-SP cells, and significantly increase the percentage of DP cells in the SEB group compared with that in the PBS group, but had no effect on DN cells in the two groups. These data suggested that prenatal exposure of SEB was not able to alter the transition of thymocytes from DN cells to DP cells, however, significantly reduced the maturation of thymocytes from DP cells to SP cells.

In order to investigate clonal anergy/deletion, the advantage of the specificity of certain TCR V $\beta$ domains for endogenous or exogenous SAgs has been documented $(13,20)$. SEB is a SAg that stimulates T cells bearing V $\beta 3,7,8.1-3$ TCR $(21,22)$, particularly V $\beta 8$ TCR in rodent animals (23). Injection of SEB into naive mice induced specific tolerance associated with a selective deletion of peripheral V $\beta 8$ cells by apoptosis $(15,16,24,25)$. The SEB injection induced an initial activation and proliferation of the $\mathrm{T}$ cells expressing appropriate $\mathrm{V} \beta$ elements. This early and transient phase of activation was followed by a second phase of cell deletion resulting in a state of SEB-specific functional $\mathrm{T}$ cell inactivation (clonal anergy) $(12,13)$, in the central and peripheral compartments. Furthermore, the remaining SEB-specific T cells became anergic and were hyporesponsive to SEB restimulation $(16,25)$. The present study revealed that prenatal exposure of SEB was able to induce a decrease in $\mathrm{V} \beta 8.2^{+} \mathrm{T}$ cells in the thymus of neonatal rats, which is consistent with other results from adult mice $(23,24)$. These results suggested that prenatal exposure of SEB was able to induce the deletion of $\mathrm{V} \beta 8.2^{+}$ $\mathrm{T}$ cells in the neonatal thymus. Furthermore, the data from in vitro culture of the neonatal thymus with SEB restimulation demonstrated that the percentage of $\mathrm{V} \beta 8.2^{+} \mathrm{T}$ cells was significantly decreased in the SEB group compared with that in the PBS group. These results suggested that SEB restimulation was able to further induce the deletion of the remaining SEB-specific $\mathrm{T}$ cells in neonatal rats exposed prenatally to SEB, which was consistent with the results in adult animals that the remaining SEB-specific T cells are anergic to SEB restimulation $(16,25)$. To the best of our knowledge, this is the first study to report the special response pattern of the remaining SEB-specific T-cells to SEB restimulation in neonatal rats exposed prenatally to SEB.

\section{Acknowledgements}

The authors would like to thank Dr Bai-qing Li (Department of Immunology, Bengbu Medical College, Bengbu, Anhui, China) for his assistance in FACS analysis and Dr Jiu Jiang (Drexel University College of Arts and Sciences, Philadelphia, PA, USA) for his asssistance with the English. This study was supported by grants from the National Science Foundation of China (no. 81070506).

\section{References}

1. Germain RN: T-cell development and the CD4-CD8 lineage decision. Nat Rev Immunol 2: 309-322, 2002.

2. Kondo M, Weissman IL and Akashi K: Identification of clonogenic common lymphoid progenitors in mouse bone marrow. Cell 91: 661-672, 1997.

3. Gameiro J, Nagib P and Verinaud L: The thymus microenvironment in regulating thymocyte differentiation. Cell Adh Migr 4: 382-390, 2010.

4. Boehm T and Bleul CC: Thymus-homing precursors and the thymic microenvironment. Trends Immunol 27: 477-484, 2006.

5. Kawamoto H, Ohmura K, Fujimoto S, et al: Extensive proliferation of $\mathrm{T}$ cell lineage-restricted progenitors in the thymus: an essential process for clonal expression of diverse $\mathrm{T}$ cell receptor beta chains. Eur J Immunol 33: 606-615, 2003.

6. Petrie HT, Tourigny M, Burtrum DB and Livak F: Precursor thymocyte proliferation and differentiation are controlled by signals unrelated to the pre-TCR. J Immunol 165: 3094-3098, 2000.

7. Bleul CC and Boehm T: BMP signaling is required for normal thymus development. J Immunol 175: 5213-5221, 2005.

8. Ishifune C, Maekawa Y, Nishida J, et al: Notch signaling regulates the development of a novel type of Thyl-expressing dendritic cell in the thymus. Eur J Immunol 41: 1309-1320, 2011.

9. Pearse M, Wu L, Egerton M, et al: A murine early thymocyte developmental sequence is marked by transient expression of the interleukin 2 receptor. Proc Natl Acad Sci USA 86: 1614-1618, 1989.

10. Bergdoll MS: Enterotoxins. In: Staphylococci and staphylococcal infections. Easman CSF and Adlam C (eds). Vol 2. Academic Press, London, 1983.

11. Bell SJ and Buxser SE: Staphylococcal enterotoxin B modulates $\mathrm{V}$ beta $8^{+} \mathrm{TcR}$-associated T-cell memory against conventional antigen. Cell Immunol 160: 58-64, 1995.

12. MacDonald HR, Baschieri S and Lees RK: Clonal expansion precedes anergy and death of $\mathrm{V}$ beta $8^{+}$peripheral $\mathrm{T}$ cells responding to staphylococcal enterotoxin B in vivo. Eur J Immunol 21: 1963-1966, 1991.

13. Seth A, Stern LJ, Ottenhoff TH, et al: Binary and ternary complexes between T cell receptor, class II MHC and superantigen in vitro. Nature 369: 324-327, 1994.

14. Lin YS, Lei HY, Low TL, et al: In vivo induction of apoptosis in immature thymocytes by staphylococcal enterotoxin B. J Immunol 149: 1156-1163, 1992.

15. Li J, Zhou YB, Zhang Y, Zhang J and Chen WF: Cloning deletion of mouse medullary CD4 SP thymocyte subgroups induced by superantigen staphylococcal enterotoxin B. Beijing Da Xue Xue Bao 40: 557-561, 2008 (In Chinese). 
16. Goettelfinger P, Roussin R, Lecerf F, Berrih-Aknin S and Fattal-German $\mathrm{M}$ : $\mathrm{T}$ cell deletion and unresponsiveness induced by intrathymic injection of staphylococcal enterotoxin B. Transpl Immunol 8: 39-48, 2000.

17. Nitta T, Ohigashi I and Takahama Y: The development of $\mathrm{T}$ lymphocytes in fetal thymus organ culture. Methods Mol Biol 946: 85-102, 2013.

18. Allman D, Sambandam A, Kim S, et al: Thymopoiesis independent of common lymphoid progenitors. Nat Immunol 4: 168-174, 2003.

19. Chen W: The late stage of T Cell development within mouse thymus. Cell Mol Immunol 1: 3-11, 2004.

20. Dowd JE, Jenkins RN and Karp DR: Inhibition of antigen-specific $\mathrm{T}$ cell activation by staphylococcal enterotoxins. J Immunol 154 $1024-1031,1995$

21. White J, Herman A, Pullen AM, et al: The V beta-specific superantigen staphylococcal enterotoxin B: stimulation of mature T cells and clonal deletion in neonatal mice. Cell 56: 27-35, 1989.
22. Herman A, Kappler JW, Marrack P and Pullen AM: Superantigens: mechanism of T-cell stimulation and role in immune responses. Annu Rev Immunol 9: 745-772, 1991.

23. Pullen AM, Marrack P and Kappler JW: The T-cell repertoire is heavily influenced by tolerance to polymorphic self-antigens. Nature 335: 796-801, 1988.

24. Kawabe Y and Ochi A: Programmed cell death and extrathymic reduction of $\mathrm{V}$ beta8 ${ }^{+} \mathrm{CD} 4^{+} \mathrm{T}$ cells in mice tolerant to Staphylococcus aureus enterotoxin B. Nature 349: 245-248, 1991.

25. Rellahan BL, Jones LA, Kruisbeek AM, Fry AM and Matis LA: In vivo induction of anergy in peripheral $V$ beta $8^{+} \mathrm{T}$ cells by staphylococcal enterotoxin B. J Exp Med 172: 1091-1100, 1990. 